\title{
Post-occupancy evaluation correlated with building occupants' satisfaction: An approach to performance evaluation of government and public buildings
}

Received (in revised form): 22nd July, 2008

\begin{abstract}
Abdul Hadi Nawawi
is currently an associate professor and head of the Centre of Postgraduate Studies, Faculty of Architecture, Planning and Surveying, Universiti Teknologi MARA (UiTM), Shah Alam, Malaysia. He has working experience with the international Knight Frank and Baillieu group and is a researcher with the Mid Glamorgan County Council, Cardiff, United Kingdom. He is a Corporate Member of Malaysian Institution of Surveyors, Malaysia, a technical Member of the National Property Research Council (NAPREC) and the National Property Information Centre (NAPIC) under the Ministry of Finance Malaysia. He is a regular representative of Malaysia at the Congress of ASEAN Valuers (AVA). His main area of interest is real estate appraisal, real estate valuation knowledge engineering and modeling, and property service quality.
\end{abstract}

\section{Natasha Khalil}

is currently a lecturer at the Faculty of Architecture, Planning and Surveying, Universiti Teknologi MARA (UiTM), Sarawak, Malaysia. Her main area of interest is building and facilities management.

Correspondence: Abdul Hadi Nawawi, Centre of Postgraduate Studies, Faculty of Architecture Planning and Surveying, University Technology MARA (UiTM), Shah Alam 40450, Malaysia; Tel: +603 55211568; Fax: + 603 55211564; E-mail: abdulhadinawawi@ yahoo.com

\begin{abstract}
Post-occupancy evaluation (POE) of buildings is vitally needed to ensure that building performance of government and public buildings and facilities is sustained. POE of buildings is of utmost importance in building performance evaluation, as it comprises the technique that is used to evaluate whether a building meets the user's requirements. By using occupants as a benchmark in evaluation, the potential for improving the performance of a building is enormous. This paper discusses research with the broad aim of developing a general guideline for the POE practice, specifically for government and public buildings in Malaysia. The objectives were first, to review and analyse government and public building performance, secondly, to determine the occupants' satisfaction level and thirdly, to determine the correlation between building performance and occupants' satisfaction level. This study has revealed that 74 per cent of the aspects of building performance are highly correlated with the occupants' satisfaction. The study concludes that the proposed guideline for POE is effective, relevant and beneficial to be used by the public sector in evaluating the performance of government and public buildings in Malaysia.

Journal of Building Appraisal (2008) 4, 59-69. doi:10.1057/jba.2008.22
\end{abstract}

\section{Keywords:}

post-occupancy evaluation, government and public buildings, building performance, occupants' satisfaction, performance and occupants' correlation 


\section{INTRODUCTION}

A completed building should be able to perform its functions in the manner that will ensure satisfaction to its occupants. Generally, regular maintenance programmes are conducted after the building has been occupied to ensure that the building is functioning well at all times. By execution of maintenance programmes, the occupants will be able to use and utilise the facilities as the provision of facilities supports the business operations by the building occupants. In short, the building facilities and services must be fit for the purpose of the users. Post-occupancy evaluation (POE) is the evaluation of the performance of buildings after they have been occupied. In addition, POE provides a mechanism for understanding the mutual interaction process between buildings and users' needs and for recommending ways of improving the environment necessary to accommodate these needs. Zimring and Reizenstein (1980) defined POE as an examination of the effectiveness of occupied design environments for human users. Vischer (2002) finds that POE is used not only to determine clients' or users' satisfaction, but also to fulfil other objectives, including determining building defects, supporting design and construction criteria, supporting performance measures for asset and facility management, lowering facility lifecycle costs by identifying design errors that could lead to increased maintenance and operating costs, clarifying design objectives and improving building performance. POE research is undergoing a major shift (Zimring, 1988) whereby for greater effectiveness, the POE methodology must consider the entire building procurement lifecycle. This approach implies a strong relationship between the development of a brief for a building project and the POE stage. It serves as a tool to account for building quality, which is essential when organisations are required to demonstrate that building programmes are responsibly managed (Watson, 2003).

In relation to the title, the main purpose of this study was to propose guidelines to implement POE for public buildings in Malaysia, with regard to the building performance review and satisfaction level of the building's occupants. The analysis of findings is determined based on the POE undertaken, which comprises approaches and evaluation methodologies that address POE effectiveness, and then within the broader context of the problem of building procurement fragmentation.

\section{PROBLEM IDENTIFICATION}

The federal government is the largest owner of public buildings and facilities in Malaysia. Despite the realisation of the importance of management and maintenance of buildings and facilities, it has not been emphasised clearly and systematically which results in over-budget costing for maintenance and remedial works (Zakaria and Hamzah, 2007a). Many building defect complaints are reported in public buildings, such as the ceiling collapse in the Parliament building in 2006, leaking pipes in the Mahkamah Jalan Duta (Offical Court Jalan Duta, Kuala Lumpur) and fungal appearance at the Sultanah Aminah Hospital Johor in 2007. Reported cases are described chronologically from 2005 to 2007 in Table 1.

Hence, POE can be seen as a multifaceted tool to be adopted in solving problems of building and facilities management, as it evaluates the performance of buildings and facilities systematically. POE can also be seen as a systematic way to collect data and information on a particular building, but unfortunately it has not yet been undertaken for government and public buildings in Malaysia (Zakaria and Hamzah, 2007b). Among the benefits that can result from POE is the identification of successful design features that can be scrutinised repeatedly (Watson, 2003), identification of problems to mitigate or 
Table I: Chronology of defects occurrence in government and public buildings

\begin{tabular}{ll}
\hline Date/year & Chronology of defects occurence \\
\hline April 2005 & Collapsed ceiling at parliament building \\
Year 2006* & Fungus infection on wall at Hospital Sultanah Aminah, Johor Bharu \\
Year 2007* & Defects at Navy recruit training centre (PULAREK), Johor \\
Year 2007* & NKVE-Meru highway collapse \\
Year 2007* & Floods from 7th floor down to 2nd floor at immigration department Putrajaya \\
Year 2007* & Plaster ceiling collapse at entrepreneurial department Putrajaya \\
I 4th May, 2007 & Collapsed ceiling at the new court complex in Jalan Duta, Kuala Lumpur \\
I 7th May, 2007 & Collapsed ceiling at parliament building \\
2 Ith May, 2007 & Leaking pipes caused flooding at the new court complex in Jalan Duta, Kuala Lumpur \\
28 th May, 2007 & Collapsed ceiling at hospital sultan Abdul Halim, Sg. Petani, Kedah \\
November 2007 & Fungus infection on wall at hospital Umum Sarawak (HUS), Kuching \\
November 2007 & Fungus and spores detected on wall at hospital Temerloh (HoSHAHS) Pahang
\end{tabular}

*Exact date not available.

reduce building and facilities defects, improvement of building performance and environment, identification of redundant or unnecessary building features and empowerment of users to negotiate building issues and reduce maintenance works and cost (Vischer, 2002; Hewitt et al., 2005).

According to Preiser et al. (1988), hundreds of POEs have been conducted on a variety of building types over the last 25 years. Some solutions included increasing involvement of the organisation being studied, better presentation of results and better targeting of information to appropriate decision makers (Zimring, 1988). Preiser (1995) stated that, historically, building performance was evaluated in an informal manner, and the lessons learned were applied in the next building cycle of a similar facility type. Because of relatively slow change in the evolution of building types in the past, knowledge about their performance was passed on from generation to generation of building specialists. Therefore, building performance criteria are an expression and translation of client goals and objectives, functions and activities and the environmental conditions that are required. In relation to the evaluation of building performance using POE application, Preiser (1995) illustrates the performance concept in the building delivery process, as shown in Figure 1.

The outcome of the research to be discussed in this paper provides information to the building industry about buildings in use and abilities to determine how well a new concept of POE works for the government and public sector. The process of POE is relative to the integration of people's requirement and its workplace. Hence, POE is described as the best application strategy that needs to be adopted in evaluating the performance of government and public buildings in Malaysia.

\section{RESEARCH OBJECTIVES}

The introduction and the problem statement above led to the formulation of the research aim and objectives. The broad aim of this research was to propose a POE guideline for government and public buildings in Malaysia. In accordance with the research aim, the objectives of this study were as follows:

(a) To review and analyse the performance of government and public buildings using the proposed POE guideline.

(b) To determine the satisfaction level of the building occupants in terms of building elements, services and environment.

(c) To obtain the correlation between performance of government and public buildings and occupants' satisfaction levels. 


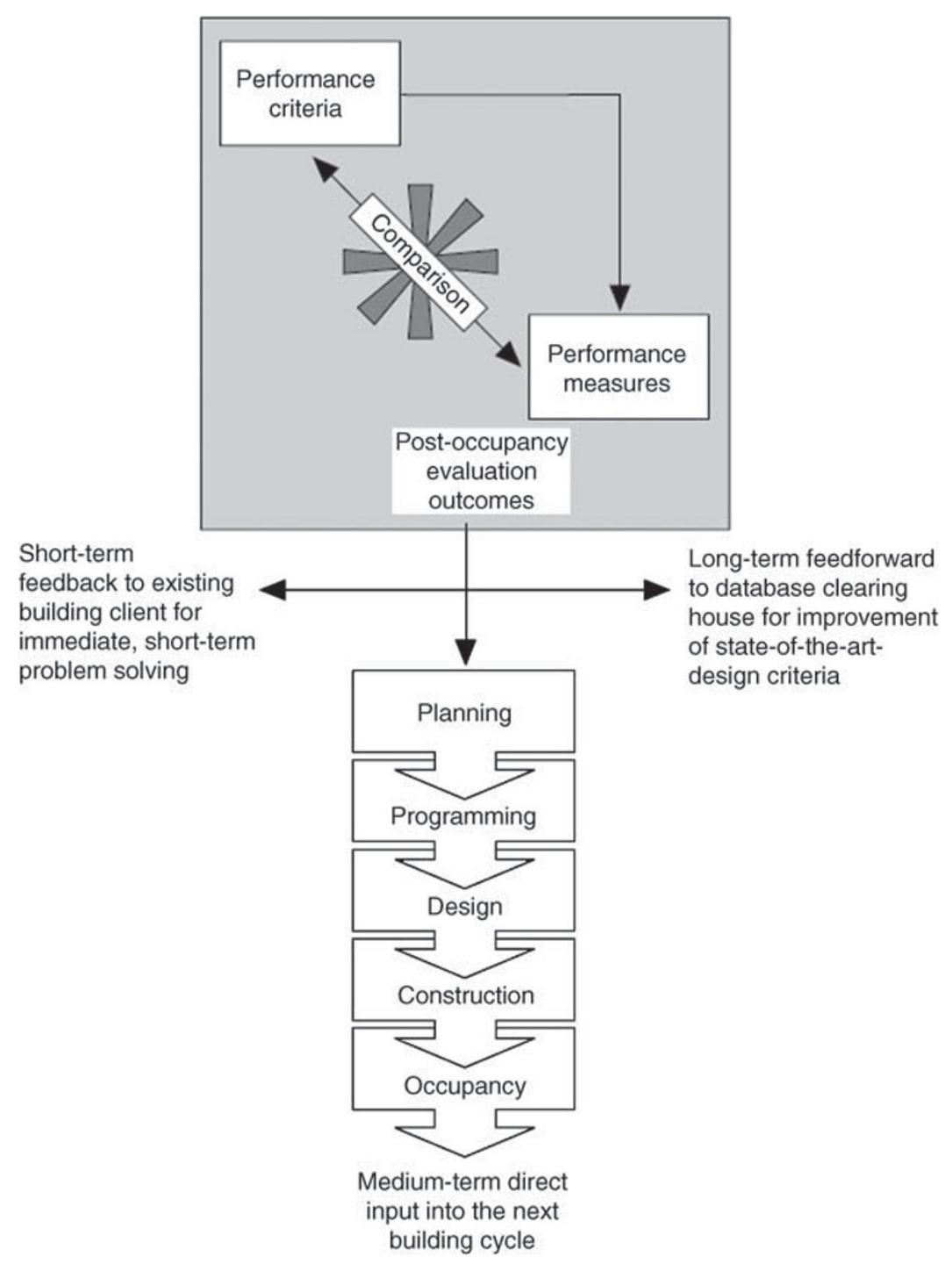

Figure I: The performance concept in the building delivery process Source: Preiser, 1995

\section{LITERATURE REVIEW}

POE as defined by Watson (2003) is a systematic evaluation of opinion about buildings in use, from the perspective of the people who use them. POEs are generally aimed at conveying the parameters of buildings that work well and also at focusing on the ones that should not be repeated in future building designs. POE describes rather than manipulates settings of building performance. The data collection of POE is usually done in actual settings rather than in laboratories. Based on the relevant parameters, POE can be categorised by its purpose to serve at various stages of a building's lifecycle.

A POE study conducted by Watson (2003) at Marlborough School Technology Centre, New Zealand found that the centre successfully supports student learning and produced key recommendations for the future. The recommendations are mainly to identify relatively simple design modifications to overcome noise control and to change teaching 
culture to suit technology curriculum. Thus, input from all building stakeholders at the planning stage is required. This helps to improve building performance when similar buildings need to be developed. The result from the POE helps to identify a measurable link between building quality and educational outcomes, which is notoriously difficult to show. Public Works Canada (1983) adopted POE for a number of different federal office buildings in Canada in order to examine the performance of the building systems. The results led to the conclusion that there are major conditions that affect users' perceptions of their level of comfort in office buildings, and this relates to the measures of performance of the technical building systems.

The Federal Facilities Council (2002) has compiled results from POE of various types of government and public buildings in the United States into a technical report. The study was conducted by six federal agencies in the US and among the objectives of such implementation is to increase building quality and performance. The summary of the findings provides input into the ongoing performance measures programmes for the offices and public buildings and enhances design improvement. Based on the above review from various source of literature and precedent research, it is clear that POE is relevant, as it indicates how well a building's performance works to satisfy the organisation's goal, as well as the needs of the individuals in the organisation. At the most fundamental level, the purpose of a building should be to provide shelter for activities that cannot be carried out as effectively in a natural environment. Only building performance evaluation has the ability to accomplish this, and POE provides the process of the actual evaluation of a building's performance once it is being used by human occupants.

Despite the large amount of research that has been carried out in the context of building performance, aspects of evaluating building performance have not been emphasised widely in Malaysia. The term POE is still new in Malaysia, and many building practitioners are still unfamiliar with this approach in evaluating building performance. POE provides an extension to other technical evaluations such as energy audit, building audit, maintenance and operation review, security inspections and other programmes developed by building and facility management in an organisation (Preiser, 2002).

Moreover, it is also essential to elicit the opinions of the buildings' occupants and correlate them with the performance level of the buildings as determined by the POE, in order to verify the credibility of POE as a building performance measurement tool. This is in line with the philosophy of the need of building and property managers to be aware of and concerned about the level of satisfaction of the buildings' occupants regarding the standard of management and maintenance of the buildings. As stated by Muhlebach (1998), in order to remain competitive a building or property manager must listen and respond to tenants' needs, concerns, expectations and opinions, and must use this information to quantify performance and compare with best practices.

\section{PROPOSED POE GUIDELINE}

The suggested guideline is derived from the analytical literature review of the study, which consists of the concept, process, phases and an in-depth review of a previous study conducted from previous research. The proposed guideline is illustrated in Figure 2. This guideline consists of a systematic sequence of six steps: identification of building parameters, evaluation of objectives, selection of planning approach, conduction of POE inspection, application of findings and actions in response to feedback. The steps fall within three phases, namely the initial phase, the process phase and the recommendation phase. Each phase illustrates issues or activities that need to be addressed in POE. This 


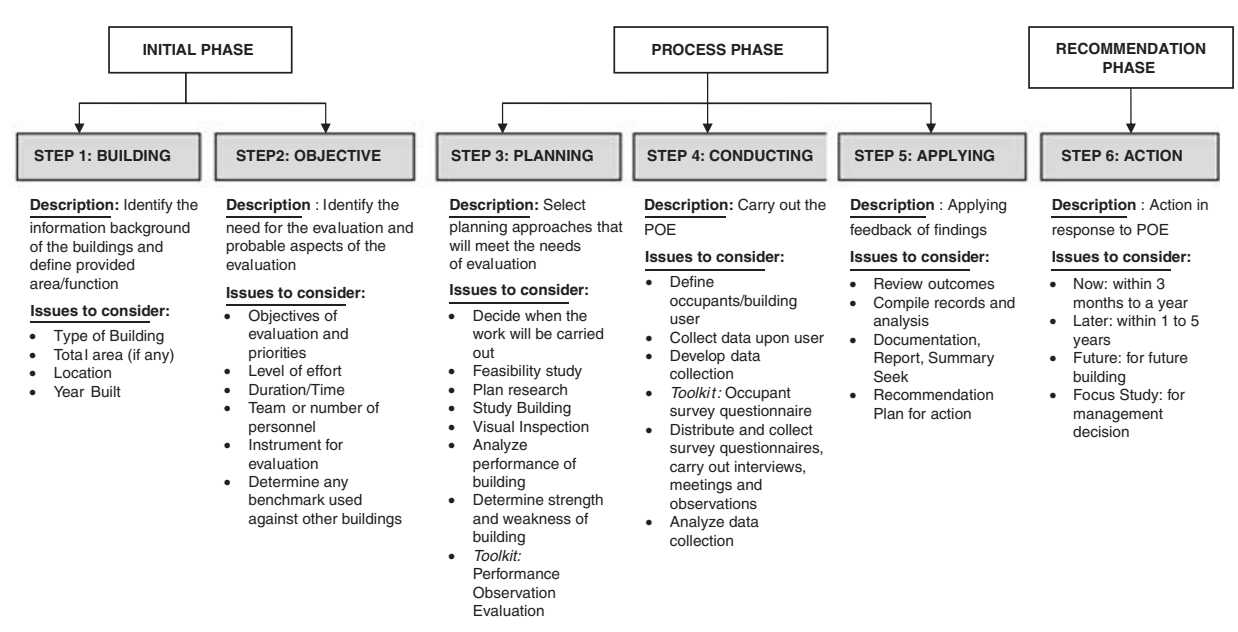

Figure 2: Proposed guideline for POE for government and public buildings in Malaysia

guideline provides an initial framework to facilitate the application of POE for government and public buildings in Malaysia.

\section{ANALYSIS AND FINDINGS}

Based on the POE guideline, a POE inspection survey was conducted on eight selected government and public buildings in Putrajaya, the administrative urban centre of the federal government where major government and public buildings are located. The analysis of this research is divided into three sections. The first section features comparative analyses of building performance reviews, with the aim of determining the score performance under poor, medium or good performance. The second section features the presentation of results and consists of analysis of the survey findings pertaining to the satisfaction level of the surveyed building occupants in terms of building elements, services and environment. The findings were derived from the 133 replies that were received from the 160 surveys that had been distributed to the occupants of the buildings being tested. Answers obtained from the questionnaires were used to provide specific findings for the study and to provide recommendations. The final section features the correlation analysis between building performance scores and the building occupants' satisfaction score.

\section{Building performance review based on the POE guideline}

The building performance based on the POE guideline was measured using a score based on the quality of various building elements, services and environment. It denotes that the building elements, services and environment in the stipulated building fall into a scale of 10 , which constitutes a full score $(S=1.0)$. Hence, the building performance score is poor if the scale category is below $4(S \leqslant 0.4)$, medium if the scale category is $5(S=0.5)$ and good if the scale category is above $6(0.6 \geqslant S \leqslant 0.9)$. Table 2 presents the summary of results of the building performance score, based on the 19 parameters of building elements, services and environment.

The results from Table 2 show that the performance of the sample buildings is generally good (with $S \geqslant 0.60$ ). There are, however, several buildings that attain a performance score of 0.5 , which is rated as medium performance. Only Building \#6 has a poor performance in terms of air-conditioning, with a score of 0.4. This evaluation is, 
Table 2: Score for building performance review based on the POE guideline

\begin{tabular}{|c|c|c|c|c|c|c|c|c|c|}
\hline \multirow[t]{3}{*}{ No. } & \multirow{3}{*}{$\begin{array}{l}\text { Building elements, } \\
\text { services and environment }\end{array}$} & \multicolumn{8}{|c|}{ Performance score (PS) } \\
\hline & & \multicolumn{8}{|c|}{$\begin{array}{l}\text { 'Poor' if } 0.10 \leqslant P S \geqslant 0.40, \text { 'medium' if } P S=0.50 \text {, 'good' if } 0.60 \leqslant P S \geqslant 0.9 \\
\text { 'excellent' if } P S=1.0\end{array}$} \\
\hline & & Bldg \#1 & Bldg \#2 & Bldg \#3 & Bldg \#4 & Bldg \#5 & Bldg \#6 & Bldg \#7 & Bldg \#8 \\
\hline I & Floor finishes & 0.60 & 0.70 & 0.80 & 0.80 & 0.80 & 0.70 & 0.80 & 0.60 \\
\hline 2 & Wall finishes & 0.60 & 0.70 & 0.80 & 0.80 & 0.8 & 0.90 & 0.80 & 0.80 \\
\hline 3 & Ceiling finishes & 0.70 & 0.70 & 0.70 & 0.80 & 0.90 & 0.70 & 0.80 & 0.90 \\
\hline 4 & Door & 0.70 & 0.70 & 0.70 & 0.90 & 0.80 & 0.80 & 0.70 & 0.80 \\
\hline 5 & Window & 0.60 & 0.70 & 0.70 & 0.90 & 0.90 & 0.70 & 0.80 & 0.70 \\
\hline 6 & Staircase & 0.60 & 0.80 & 0.70 & 0.90 & 0.90 & 0.70 & 0.80 & 0.80 \\
\hline 7 & Roof & 0.70 & 0.60 & 0.80 & 0.70 & 0.80 & 0.60 & 0.80 & 0.70 \\
\hline 8 & Quality of finishes & 0.60 & 0.60 & 0.80 & 0.80 & 0.80 & 0.70 & 0.70 & 0.70 \\
\hline 9 & Quality of structure & 0.80 & 0.60 & 0.70 & 0.90 & 0.80 & 0.80 & 0.70 & 0.70 \\
\hline 10 & Physical maintenance & 0.50 & 0.60 & 0.50 & 0.60 & 0.60 & 0.50 & 0.70 & 0.60 \\
\hline II & Safety and security & 0.80 & 0.80 & 0.90 & 0.80 & 0.90 & 0.80 & 0.80 & 0.90 \\
\hline 12 & Level of cleanliness & 0.80 & 0.70 & 0.90 & 0.80 & 0.80 & 0.90 & 0.80 & 0.80 \\
\hline 13 & Quality of lightings & 0.60 & 0.70 & 0.60 & 0.70 & 0.80 & 0.50 & 0.70 & 0.60 \\
\hline 14 & Air-conditioning & 0.80 & 0.70 & 0.50 & 0.90 & 0.80 & 0.40 & 0.80 & 0.70 \\
\hline 15 & Landscaping & 0.70 & 0.80 & 0.80 & 0.80 & 0.80 & 0.70 & 0.80 & 0.80 \\
\hline 16 & Lift/Escalators & 0.60 & 0.70 & 0.60 & 0.80 & 0.90 & 0.60 & 0.80 & 0.70 \\
\hline 17 & Electrical and Mechanical & 0.60 & 0.70 & 0.50 & 0.60 & 0.80 & 0.70 & 0.70 & 0.60 \\
\hline 18 & Water and plumbing services & 0.60 & 0.60 & 0.60 & 0.70 & 0.80 & 0.60 & 0.70 & 0.70 \\
\hline 19 & Noise pollution or vibration & 0.60 & 0.60 & 0.80 & 0.80 & 0.90 & 0.50 & 0.80 & 0.80 \\
\hline
\end{tabular}

however, conducted based on a one-time study visit and observation. The score needs to be compared with the building occupants' satisfaction score, as they had sufficient time to experience the performance of the buildings, and hence were able to identify any chronic problems.

\section{Occupants' satisfaction level}

Section B of the questionnaire was designed to determine the satisfaction level of the building occupants on the 19 parameters, as stated earlier in Table 2, based on a Likert scale from 1 to 5, where 1 was Very Unsatisfied and 5 was Very Satisfied.

The calculation of the scores for occupants' satisfaction is based on the 19 parameters listed in Section B of the questionnaire.

The formula generated to calculate the satisfaction score is illustrated as follows:

$$
\mathrm{SS}=\frac{\operatorname{RS}\left[N^{5}+N^{4}+N^{3}+N^{2}+N^{1}\right]}{\operatorname{FS}\left[\operatorname{Total} N^{5}\right]}
$$

where SS is the satisfaction score, RS the relative score, FS the full score, $N$ the no. of respondents, $N^{5}, N^{4}, N^{3}, N^{2}, N^{1}$ the (no. of respondents answered for Likert scale)× (Likert scale).

Table 3 presents the summary of the building occupants' satisfaction score for each building.

\section{Correlation coefficient of building performance and occupants' satisfaction}

The final section of the analysis involves finding the correlation coefficient of the building occupants' satisfaction in relation to the building performance. The correlation analysis 


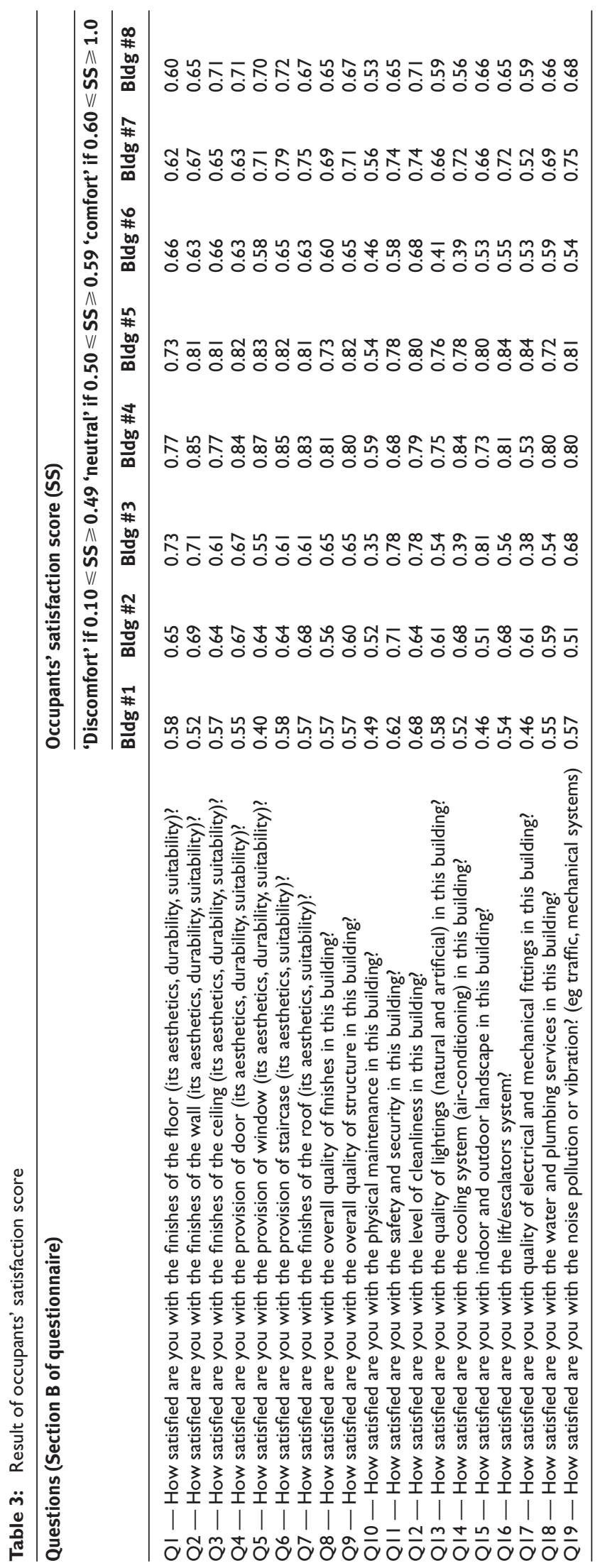


was undertaken using Kendall's tau correlation. The analysis of the correlation was conducted using the statistical software program Statistical Packages for the Social Sciences (version 12.00). The hypotheses were statistically tested with a two-tailed alpha level of 0.05 . The correlation analysis was undertaken in order to see whether building performance correlates with the level of building occupants' based on the 19 parameters stipulated in the questionnaires. High correlation between building performance and building occupants' satisfaction indicates that the proposed guideline is effective and relevant for use in evaluating the performance of government and public buildings in Malaysia. The correlation coefficients are presented in Figure 3 and are explained as follows:

\section{Region A - very high correlations (top):}

The correlation between building performance scores and the building occupants' satisfaction scores is positively very high for the parameters windows, staircases, lighting and lifts. The very high correlation coefficients show that performance review based on the POE of these parameters has a very strong positive relationship with the building occupants' satisfaction level.

\section{Region B - high correlations (middle):}

The correlation between building performance scores and the building occupants' satisfaction scores is positively high for the parameters floor finishes, ceiling finishes, doors, quality of finishes, maintenance, air-conditioning, landscape, quality of M\&E fittings, water services and noise control. The high correlation coefficients show that performance review based on the POE of these parameters has a strong positive relationship with the building occupants' satisfaction level.

\section{Region C - low correlations (bottom):}

The correlation between building performance scores and the building occupants is positively low for the parameters wall finishes, roof, quality of structure, safety and cleanliness. Nevertheless, despite having low correlations, they do not constitute negative

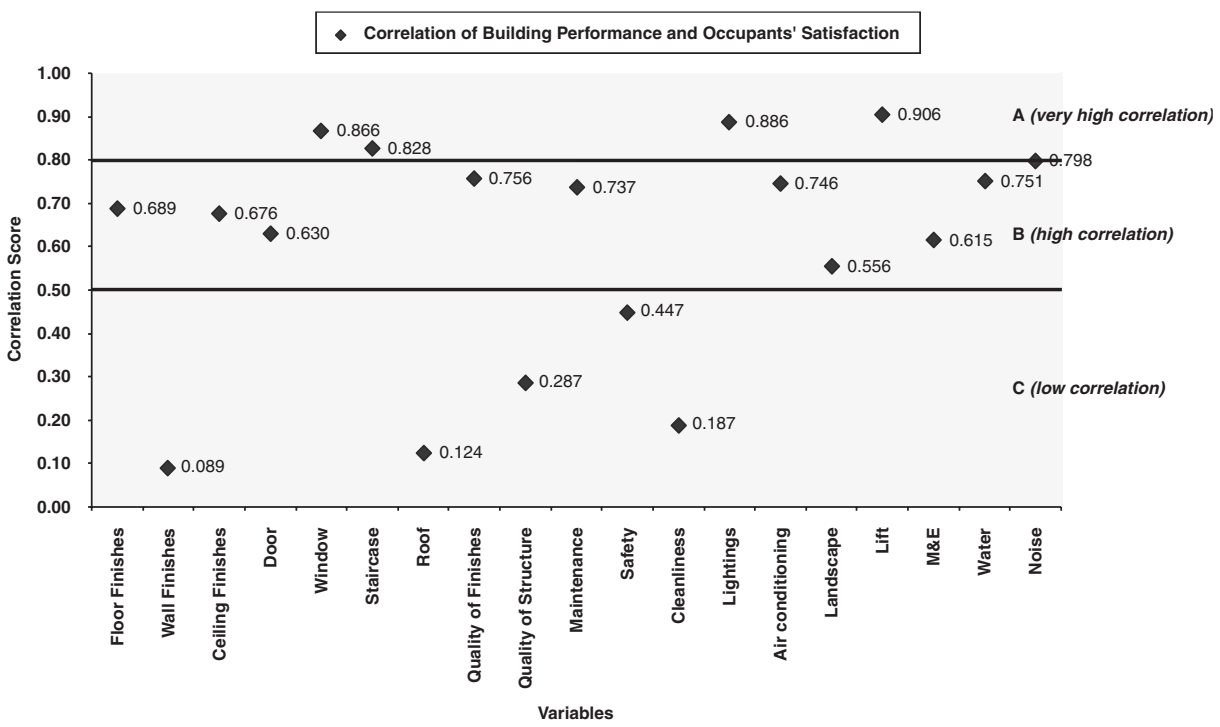

Figure 3: Correlation between building performance ad occupants' satisfaction using Kendall's tau correlation 
correlations. The possible explanation for these low correlations is the difference in perception between the building occupants and the assessment made from the POE guideline on the performance levels of these parameters. The occupants have different perceptions and expectations of the outlined parameters, which are influenced by their backgrounds, working experiences, general knowledge and technical skills. This finding highlights the need for further investigations into the details of the parameters included in the POE guideline, in order to ensure that they are in tandem with the building occupants' satisfaction levels. This may involve refining the parameter details in the POE guideline.

Based on Figure 3, the correlations show that 74 per cent of the parameters or variables are in the region of very high and high correlations between building performance scores and building occupants' satisfaction scores. Since the majority of the parameters are in very high and high correlations, it can therefore be concluded that the proposed guideline for POE is effective and relevant for government and public buildings in Malaysia.

\section{CONCLUSIONS}

POE provides a valuable approach to analysing the performance of government and public buildings in Malaysia. Analysis of the findings confirms that the application of POE is relevant, effective and successful in determining occupants' satisfaction level, as well as providing recommendations for improving building performance. The approach has great potential for analysing building performance, as it uses a strategic approach to achieve the best quality in building services, whereby the building occupants' behaviour, perceptions and opinions are integrated.

Clearly, POE is a useful tool for building asset and facilities management, as long as the approach employed to collect feedback from users is effectively integrated towards sustainability of government and public buildings. POE also seems to have a natural place in strategic planning of building management and can be developed under the public sector. The key to this application is allocating the needs of POE in the building design and planning phase. The research also noted that many ideas and solutions are being developed to achieve buildings' sustainability and these can create an opportunity for wider application of POE, especially for government and public buildings. POE is able to mitigate the emergence of defective problems, as the process allows strategic assessment to building current performance. More importantly, the design of the buildings should also consider parameters that will determine the effective performance of the buildings in line with high satisfaction and comfort to the buildings' occupants.

The findings of the research have also outlined the important considerations and recommendations towards improving the performance of the government and public buildings. As the findings have shown, the majority of the parameters or aspects in building performance (building elements, services and environment) have a high correlation with the building occupants' satisfaction levels. Hence, the POE guideline is recommended for use in improving the performance of government and public buildings in Malaysia.

\section{References}

Federal Facilities Council (2002) Learning from Our Buildings: A State of the Practice Summary of Post Occupancy Evaluation, Federal Facilities Council, National Academy Press, Washington. 
Hewitt, D., Higgins, C. and Heatherly, P. (2005) A Market-Friendly Post Occupancy Evaluation:Building Performance Report, New Buildings Institute, Inc, Washington.

Muhlebach, R.F. (1998) 'Tenant surveys benchmark success for management firms', National Real Estate Investor, 40(2), 159-160.

Preiser, W.F.E. (1995) 'Post occupancy evaluation: how to make buildings work better', Journal of Facilities, 13(11), $19-28$.

Preiser, W.F.E. (2002) The Evolution of Post Occupancy Evaluation: Towards Building Performance and Design Evaluation, Federal Facilities Council, National Academy Press, Washington, Chapter 2, pp. 9-22.

Preiser, W.F.E., Rabinowits, H.Z. and White, E.T. (1988) Post Occupancy Evaluation, Van Nostrand Reinhold Company CRS Sirrine Houston, TX, New York.

Public Works Canada (1983) Stage One in the Development of Total Building Performance 12 Volumes, Architectural and Building Sciences, Ottawa.

Vischer, J. (2002) Post Occupancy Evaluation: A Multifaced Tool for Building Improvement, Federal Facilities Council, The National Academy Press, US, Chapter 3, pp. 23-34.

Watson, C. (2003) 'Review of building quality using post occupancy evaluation', Journal of Programme Education Building, 35, 1-5.

Zakaria, A. and Hamzah, S. (2007a) 'Pelan Kualiti Dapat Elak Projek Hadapi Masalah: Majlis Aset Kebangsaan Mampu Tingkatkan Kecekapan Penyelenggaraan', Berita Harian, 15th August, 2007, p. 2.

Zakaria, A. and Hamzah, S. (2007b) 'Sektor Awam Perlu Bantu', Berita Harian, 14th August, 2007, p. 3.

Zimring, C. (1988) 'Post-occupancy evaluation and implicit theories of organizational decision-making. The Proceedings of the 19th Annual Conference of the Environmental Design Research Association. Pomona, CA., pp. 277-280.

Zimring, C. and Reizenstein, J.E. (1980) 'Post-occupancy evaluation: an overview', Environment and Behavior, 12, $429-451$. 